\title{
Pengembangan Instrumen Asesmen Higher Order Thinking SKILL (HOTS) pada Materi Himpunan Kelas VII SMP
}

\author{
Santi Arum Puspita Lestari \\ Universitas Buana Perjuangan Karawang
}

\section{INFO ARTICLES}

\section{Article History:}

Received: 26-May-2019

Revised: 15-June-2019

Approved: 20-June-2019

Publish Online: 26-June-2019

\section{KeyWords:}

Instrumen, Asesmen, Higher Order Thinking (HOTS), Himpunan

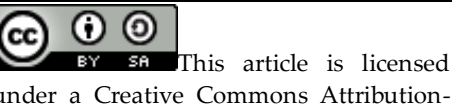

under a Creative Commons AttributionShareAlike 4.0 International License.

\begin{abstract}
This study aims to develop a HOTS valid and reliable assessment instrument on set material that can measure the high-level abilities of class VII junior high school students. The method used is developmental research. The product developed is a HOTS assessment instrument in the form of a test question. The study population was all junior high schools in the city of Karawang with a sample of 4 schools randomly. The research data comes from qualitative and quantitative data. Qualitative data was obtained from the results of the validation of experts involving 3 mathematical education experts. Quantitative data was obtained from the results of limited trials and field trials. Based on the results of the study, it can be concluded that this study produced a product in the form of a HOTS assessment instrument that can measure the high-level thinking skills of class VII junior high school students. The assessment instrument consisted of 15 multiple choice questions and 5 essay questions. The instrument proved to be highly reliable so that the instrument meets the requirements of a good instrument. While the level of difficulty of the instrument is relatively moderate and the distinguishing power of the problem includes the criteria of good
\end{abstract}

Abstrak : Penelitian ini bertujuan untuk mengembangkan instrumen asesmen HOTS yang valid dan reliabel pada materi himpunanyang dapat mengukur kemampuan tingkat tinggi siswa SMP kelas VII.Metode yang digunakan adalah penelitian pengembangan (developmental research). Produk yang dikembangkan adalah instrumen asesmen HOTS yang berupa soal tes. Populasi penelitian adalah seluruh SMP yang ada di kota Karawang dengan sampel sebanyak 4 sekolah secara acak. Data penelitian berasal dari data kualitatif dan kuantitatif. Data kualitatif diperoleh dari hasil validasi para ahli yang melibatkan 3 ahli pendidikan matematika. Data kuantitatif diperoleh dari hasil uji coba terbatas dan uji coba lapangan. Berdasarkan hasil penelitian, dapat disimpulkan bahwa penelitian ini menghasilkan produk berupa instrumen asesmen HOTS yang dapat mengukur kemampuan berpikir tingkat tinggi siswa SMP kelas VII.Instrumen asesmen berupa 15 soal pilihan ganda dan 5 soal essay. Instrumen terbukti reliabel tinggi sehingga instrumen sudah memenuhi persyaratan instrumen yang baik. Sedangkan tingkat kesukaran instrumen tergolong sedang dan daya pembeda soal temasuk kriteria baik.

Correspondence Address:Jln. H.S. Ronggowaluyo, Telukjambe Timur Karawang 4136; e-mail: santi.arum@ubpkarawang.ac.id

How to Cite (APA $6^{\text {th }}$ Style): Lestari, S. A. P. (2019). Pengembangan Instrumen Asesmen Higher Order Thinking SKILL (HOTS) pada Materi Himpunan Kelas VII SMP. JKPM (Jurnal Kajian Pendidikan Matematika), 4(2): 111-120.

Copyright:Lestari, (2019)

Competing Interests Disclosures: The authors declare that they have no significant competing financial, professional or personal interests that might have influenced the performance or presentation of the work described in this manuscript. 


\section{PENDAHULUAN}

Penilaian merupakan salah satu cara untuk mengetahui sejauh mana hasil yang telah diperoleh setelah melakukan suatu proses. Penilaian ini merupakan bagian dari asesmen kelas yakni pengukuran, penilaian, dan tes. Pada akhir proses pembelajaranakandilakukan penilaian hasil pembelajaran kepada siswa. Penilaian ini ditujukan untuk mengetahui apakah tujuan pembelajaran telah tercapai atau belum. Hasil dari penilaian kelas dijadikan sebagai tolok ukur guru dalam pembelajaran selanjutnya. Hal ini sejalan dengan pendapat Airasian (2005), yang menyatakan bahwa penilaian kelas sebagai proses mengumpulkan, memadukan, dan menginterpretasikan informasi untuk membantu peningkatan pembelajaran di kelas.

Penilaian yang baik terjadi jika ada instrumen yang baik juga. Instrumen yang baik dapat dilihat dari kualitas isi instrumen. Instrumen penilaian yang digunakan dapat berupa tes, pengamatan, penugasan individu ataupun kelompok, dan bentuk lainnya yang sesuai dengan karakteristik kompetensi pelajaran dan tingkat perkembangan siswa. Menurut Arikunto (2009) terdapat empat persyaratan instrumen yang baik yaitu: valid (sahih), reliabel (dapat dipercaya), praktis (dapat digunakan), ekonomis (tidak boros). Kadir (2015) menyatakan bahwa penyusunan instrumen yang baik dapat dilakukan dengan beberapa langkah berikut:

1. Merujuk pada silabus,

2. Menyusun kisi-kisi soal,

3. Menyusun soal,

4. Melaksanakan uji coba tes,

5. Membuat pedoman penskoran

Walaupun sudah dilakukan penilaian tapi sering kali hasilnya masih tidak sesuai dengan kompetensi lulusan. Hal ini terjadi karena instrumen asesmen yang digunakan kurang variatif dan hanya seputar pemahaman terhadap materi pelajaran.Instrumen dengan tingkat pemahaman masih termasuk pada kelompok tingkat berpikir rendah sehingga kemampuan siswa kurang berkembang. Namun realisasinya, guru masih menggunakan instrumen yang biasa saja dalam penilaian atau asesmen kelas. Oleh karena itu, instrumen yang digunakan dalam penilaian atau asesmen harus mencakup kemampuan pemecahan masalah, berpikir kritis dan kreatif, kemampuan berargumen, dan pengambilan keputusan. Semua kemampuan tersebut dapat dicapai dengan instrumen Higher Order Thinking Skill (HOTS). Instrumen HOTS merupakan instrumen pengukuran yang digunakan untuk mengukur kemampuan berpikir tingkat tinggi, yaitu kemampuan berpikir yang tidak sekedar mengingat dan menyatakan kembali maupun merujuk tanpa melakukan pengolahan.

Resnick (1987) menyatakan bahwa konsep HOTS sebagai non-algoritmik, kompleks, diperoleh berbagai solusi, membutuhkan aplikasi berbagai kriteria, regulasi-diri dalam kemandirian. Hal serupa juga dipaparkan oleh NCTM (1989) bahwa HOTS sebagai dukungan pada solusi terhadap non-routine problem. Dengan demikian, siswa diminta untuk menyelesaikan masalah-masalah dengan beberapa cara penyelesaian. Stein dan Lane (1996)juga menekankan bahwa HOTS melibatkan penggunaan konsep yang kompleks, berpikir algoritmik untuk menyelesaikan tugas, instruksi tugas atau pekerjaan yang tidak bisa diprediksi.

Instumen HOTS mengukur dimensi metakognitif yang menggambarkan kemampuan menghubungkan beberapa konsep yang berbeda, menginterpretasikan, memecahkan masalah, memilih strategi pemecahan masalah, menemukan metode baru, berargumen, dan mengambil keputusan yang tepat.Dimensi proses berpikir pada Taksonomi Bloom (Anderson \& Krathwohl, 2001)terdiri dari kemampuan mengetahui (C1), memahami (C2), menerapkan (C3), menganalisis (C4), mengevaluasi (C5), dan mengkreasi/menciptakan (C6). Instrumen HOTS akan mengukur kemampuan level C4 sampai dengan C6 Untuk lebih jelasnya perhatikan tabel dimensi proses berpikir berikut. 
Tabel 1. Dimensi Proses Berpikir

\begin{tabular}{cll}
\hline Higher Order & C6 - Mengkreasi & Mengkreasi ide /gagasan sendiri. \\
\cline { 2 - 3 } Thinking Skill & C5-Mengevaluasi & Mengambil keputusan sendiri. \\
\cline { 2 - 3 } & C4-Menganalisis & Menspesifikasi aspek-aspek atau elemen. \\
\hline Medium Order & C3-Mengaplikasi & Menggunakan informasi pada domain berbeda. \\
\cline { 2 - 3 } Thinking Skill & C2 - Memahami & Menjelaskan ide/konsep. \\
\hline Lower Order & C1 - Mengetahui & Mengingat kembali. \\
Thinking Skill & & \\
\hline
\end{tabular}

Ada tiga karakteristik soal-soal HOTS. Pertama adalah mengukur kemampuan tingkat tinggi yaitu kemampuan untuk memecahkan masalah (problem solving), keterampilan berpikir kritis (critical thinking), berpikir kreatif (creative thinking), kemampuan berargumen (reasoning), dan kemampuan mengambil keputusan (decision making). Kedua adalah berbasis permasalahan kontekstual, maksudnya asesmen harus berbasis situasi nyata dalam kehidupan sehari-hari siswa.Ketigaadalah menggunakan bentuk soal yang beragam.

\section{METODE}

Metode yang digunakan dalam penelitian ini adalah penelitian pengembangan (developmental research). Produk yang dikembangkan adalah instrumen asesmen HOTS yang berupa soal tes. Penelitian ini mengadaptasi model pengembangan Borg dan Gall (1983), yang hanya mengambil tujuh langkah saja.

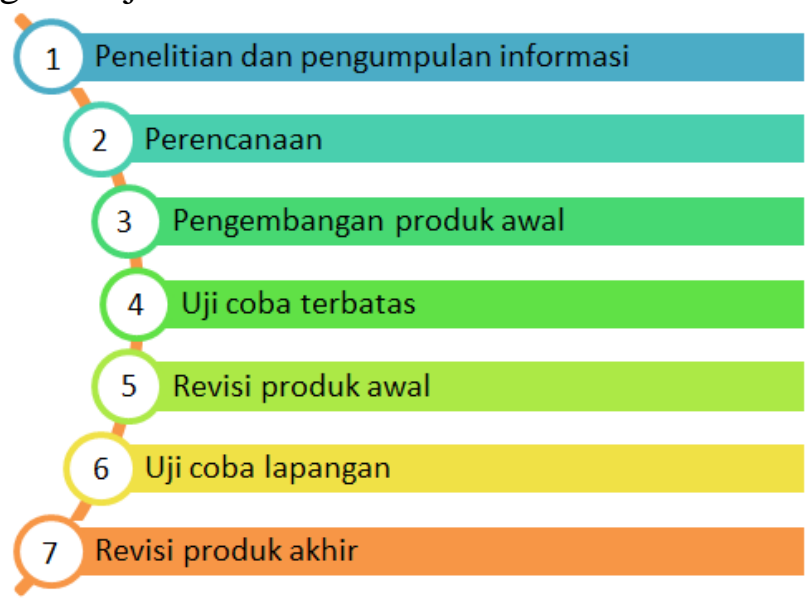

Gambar 1. Model Pengembangan Instrumens HOTS

Populasi penelitian ini adalah seluruh SMP yang ada di kota Karawang. Sampel yang dipilih sebanyak 4 sekolah yang ada di Karawang secara acak. Sampel tersebut merupakan siswa-siswa kelas VII SMP. Setiap sampel akan diberikan soal HOTS yang sama. Teknik pengumpulan data instrumen tes HOTS antara lain:

1. Menyusun instrumen yang terdiri dari kisi-kisi soal, soal tes HOTS, rubrik penskoran.

2. Menentukan validitas isi instrumen dengan expert judgment.

3. Melakukan revisi instrumen.

4. Melakukan uji coba instrumen tes HOTS.

5. Menetukan reliabilitas, tingkat kesukaran, dan daya pembeda butir soal tes HOTS. 
Validasi instrumen tes dilakukan pada tahap pengembangan soal dengan melibatkan 3 ahli pendidikan matematika. Selain itu, uji empiris menggunakan cara uji coba terbatas dan uji coba lapangan. Uji coba terbatas dilakukan pada 35 siswa SMP Negeri 5 Karawang sedangkan uji coba lapangan dilakukan pada 152 siswa SMP antara lain: SMP Negeri 1 Telukjambe Timur, SMP Negeri 2 Telukjambe Timur, SMP Negeri 1 Karawang Barat, SMP Negeri 2 Karawang Barat.

Data penelitian berasal dari data kualitatif dan kuantitatif. Data kualitatif diperoleh dari hasil validasi dari para ahli mengenai instrumen tes HOTS. Data kuantitatif diperoleh dari hasil uji coba terbatas dan uji coba lapangan.Instrumen tes HOTS dianalaisis secara kualitatif dengan mengukur kevalidan soal. Validasi ditinjau dari tiga aspek, yaitu materi, konstruksi, dan bahasa. Soal tes valid atau layak digunakan berdasarkan penilaian dari validator. Kriteria validasi butir soal menggunakan tiga pilihan yaitu layak digunakan, perlu diperbaiki, dan perlu diganti untuk setiap nomor butir soal. Instrumen untuk mengukur reliabilitas digunakan dua jenis soal tes yaitu soal pilihan ganda (15 soal) dan soal essay (5 soal). Soal tes HOTS diujikan secara individu dan hasilnya dianalisis secara kuantitatif untuk mengetahui estimasi koefisien reliabilitas instrumen asesmen yang dikembangkan. Instrumen asesmen HOTS yang dikembangkan berfokus pada materi himpunan kelas VII SMP. Materi yang dinilai adalah himpunan bagian, diagram venn, dan aplikasi himpunan.

Indikator tes HOTS yang digunakan dalam penelitian antara lain: 1) mengidentifikasi dan mengaitkan informasi yang relevan dari suatu masalah, 2) membuat kesimpulan yang tepat berdasarkan informasi dari situasi atau masalah, 3) menemukan konsistensi atau inkonsistensi dalam suatu operasi atau produk, 4) menilai suatu operasi atau produk yang relevan berdasarkan kriteria, 5) menggabungkan ide/strategi untuk menyelesaikan masalah, 6) menggunakan ide/strategi yang tepat untuk menyelesaikan masalah, 7) mengembangkan atau membuat alternatif baru dalam menyelesaikan masalah.

\section{HASIL}

Pengembangan instrumen asesmen HOTS dimulai dengan merancang soal tes dengan indikator yang telah ditentukan sebelumnya. Produk awal instrumen soal HOTS ini kemudian divalidasi secara isi atau konten oleh validator ahli. Validator dari ahli matematika menilai apakah instrumen soal HOTS yang telah dibuat sudah sesuai dengan indikator dan kaidah pembuatan soal. Sedangkan validator dari guru SMP menilai apakah instrumen soal HOTS sudah sesuai dengan materi himpunan dan bahasanya dimengerti oleh siswa. Hasil revisi instrumen dari validator ahli kemudian diujicobakan secara terbatas kepada siswa. Uji coba terbatas ini dilakukan untuk memperoleh perkiraantingkat kesukaran, reabilitas, dan daya pembeda instrumen HOTS. Hasil revisi dari uji coba lapangan digunakan sebagai produk utama instrumen asesmen HOTS.

Instrumen tes HOTS awal divalidasi Instrumen HOTS awal divalidasi oleh validator ahli beserta kisi-kisinya. Hasil validasi kemudian dianalisis menggunakan rumus Aiken's V untuk mengetahui validitas isi dari instrumen.Berikut hasil analisis terdapat pada Tabel 2.

Tabel 2. Hasil Analisis Validitas Ahli Intrumen Tes HOTS

\begin{tabular}{cccc}
\hline Instrumen & Butir Soal & Koefisien Aiken's V & Kriteria \\
\hline Pilihan Ganda & $1-15$ & $0,7-1,00$ & Layak digunakan \\
\hline Essay & $1-5$ & $0,65-0,98$ & Layak digunakan \\
\hline
\end{tabular}

Pada Tabel 2 terlihat bahwa semua instrumen tes baik pilihan ganda dan essay dinyatakan valid. Namun, instrumen tes tetap direvisi berdasarkan masukan dan saran dari validator. Revisi 
berupa penyesuaian kalimat agar dimengerti siswa, perbaikan gambar, serta informasi data pada instrumen tes. Instrumen tes awal kemudian diujicobakan secara terbatas kepada beberapa siswa. Pada uji coba terbatas analisis yang dilakukan adalah tingkat kesukaran, daya pembeda, dan reabilitas soal. Berikut penjelasannya.

Tabel 3. Tingkat Kesukaran Instrumen Tes HOTS Awal Pilihan Ganda

\begin{tabular}{lcc}
\hline \multicolumn{1}{c}{ Butir Soal } & Kategori & Persentase $(\%)$ \\
\hline $5,9,10,11,15$ & Sukar & 33,33 \\
$2,3,4,6,7,8,12,13,14$ & Sedang & 60 \\
1 & Mudah & 6,67 \\
\hline
\end{tabular}

Tabel 3 menunjukkan bahwa terdapat 1 butir soal pilihan ganda dengan kategori mudah $(6,67 \%)$, 9 soal termasuk kategori sedang (60\%), dan 5 soal berkategori sukar $(33,33 \%)$. Selain tingkat kesukaran, daya pembeda soal pilihan ganda dijelaskan sebagai berikut.

Tabel 4. Daya Pembeda Instrumen Tes HOTS Awal Pilihan Ganda

\begin{tabular}{lcc}
\hline \multicolumn{1}{c}{ Butir Soal } & Kategori & Persentase (\%) \\
\hline- & Baik & \\
$1,2,4,5,6,7,8,9,11,12,13,14$ & Diterima tanpa revisi & 80 \\
$3,10,15$ & Diterima dengan revisi & 20 \\
- & Diganti & - \\
\hline
\end{tabular}

Pada Tabel 4 terlihat bahwa ada sebanyak 12 soal diterima tanpa revisi, sedangkan soal yang perlu direvisi ada sebanyak 3 . Berikut adalah ringkasan analisis instrumen tes pilihan ganda.

Tabel 5. Statistik Hasil Analsis Instrumen Tes HOTS Awal Pilihan Ganda

\begin{tabular}{lc}
\hline \multicolumn{1}{c}{ Jenis Statistik } & Nilai Statistika \\
\hline Mean & 16,971 \\
Standar Deviasi & 5,815 \\
Koefisien Reabilitas & 0,703 \\
Rata-Rata Tingkat Kesukaran & 0,354 \\
Rata-Rata Daya Pembeda & 0,300 \\
\hline
\end{tabular}

Beradasarkan Tabel 5, koefisien reliabilitas 0,703 maka soal tes pilihan ganda memiliki reabilitas yang tinggi. Rata-rata tingkat kesukaran soal pilihan ganda adalah 0,354 berarti soalsoal pada tes ini adalah sedang. Sedangkan rata-rata daya pembeda yaitu 0,300 berarti instrumen tes pilihan ganda dapat mampu membedakan peserta didik kelompok atas dan kelompok bawah.Setelah analisis instrumen tes soal pilihan ganda, maka selanjutnya hasil analisis instrumen tes soal essay. Analisis pertama adalah tingkat kesukaran.

Tabel 6.Tingkat Kesukaran Instrumen Tes HOTS Awal Essay

\begin{tabular}{lcc}
\hline \multicolumn{1}{c}{ Butir Soal } & Kategori & Persentase (\%) \\
\hline 2,3 & Sukar & 40 \\
1,5 & Sedang & 40 \\
4 & Mudah & 20 \\
\hline
\end{tabular}


Berdasarkan Tabel 6, diperoeh hasil soal tes untuk kategori sukar dan sedang ada 2 soal (40\%) dan untuk kategori mudah ada 1 soal (20\%). Selanjutnya, analisis daya pembeda soal essay dijelaskan sebagai berikut.

Tabel 7. Daya Pembeda Instrumen Tes HOTS Awal Essay

\begin{tabular}{|c|c|c|}
\hline Butir Soal & Kategori & Persentase $(\%)$ \\
\hline- & Baik & - \\
\hline $1,3,4$ & Diterima tanpa revisi & 60 \\
\hline 2,5 & Diterima dengan revisi & 40 \\
\hline - & Diganti & - \\
\hline
\end{tabular}

Tabel 7 menunjukkan bahwa 3 soal dapat diterima tanpa revisi dan 2 soal perlu direvisi ada kembali. Ringkasan statistik untuk instrumen tes HOTS awal soal essay dijabarkan pada tabel di bawah ini.

\begin{tabular}{lc} 
Tabel 8. Statistik Hasil Analsis Instrumen Tes HOTS Awal Essay \\
\hline \multicolumn{1}{c}{ Jenis Statistik } & Nilai Statistika \\
\hline Mean & 33,943 \\
Standar Deviasi & 11,628 \\
Koefisien Reabilitas & 0,726 \\
Rata-Rata Tingkat Kesukaran & 0,437 \\
Rata-Rata Daya Pembeda & 0,420 \\
\hline
\end{tabular}

Tabel 8 menjelaskan bahwa koefisien reliabilitas instrumen tes essay adalah 0,626 maka reabilitas soal essay tinggi. Rata-rata tingkat kesukaran adalah 0,437 berarti soal-soal pada tes ini adalah sedang. Sedangkan rata-rata daya pembeda yaitu 0,420 berarti instrumen tes pilihan ganda dapat mampu membedakan peserta didik kelompok atas dan kelompok bawah.

Setelah diujicoba secara terbatas dan revisi maka selanjutnya hasil analaisis intrumen tes HOTS akhir yang diujicoba lapangan kepada 152 siswa. Analisis yang dilakukan sama seperti sebelumnya. Analisis pertama adalah tingkat kesukaran intrumen tes HOTS akhir pilihan ganda yang disajikan pada tabel berikut ini.

Tabel 9. Tingkat Kesukaran Instrumen Tes HOTS Akhir Pilihan Ganda

\begin{tabular}{lcc}
\hline \multicolumn{1}{c}{ Butir Soal } & Kategori & Persentase (\%) \\
\hline 5,11 & Sukar & 13,33 \\
$1,2,3,4,56,7,8,9,10,12,13,14$ & Sedang & 86,67 \\
- & Mudah & - \\
\hline
\end{tabular}

Pada Tabel 9 diperoleh hasil bahwa ada 2 butir soal pilihan ganda dengan kategori sukar $(13,33 \%)$, dan 13 soal termasuk kategori sedang $(86,67 \%)$. Selanjutnya mengukur daya pembeda soal pilihan ganda dijelaskan sebagai berikut.

Tabel 10. Daya Pembeda Instrumen Tes HOTS Akhir Pilihan Ganda

\begin{tabular}{lcc}
\hline \multicolumn{1}{c}{ Butir Soal } & Kategori & Persentase (\%) \\
\hline $2,4,5,8,11,14$ & Baik & 40 \\
$1,3,6,7,9,10,12,13,15$ & Diterima tanpa revisi & 60 \\
- & Diterima dengan revisi & - \\
- & Diganti & - \\
\hline
\end{tabular}


Berdasarkan Tabel 10,menunjukkan bahwa instrumen tes akhir pilihan ganda mempunyai 6 soal berkategori baik dan 9 soal diterima tanpa revisi. Berikut adalah ringkasan analisis instrumen tes akhir pilihan ganda.

Tabel 11. Statistik Hasil Analsis Instrumen Tes HOTS Akhir Pilihan Ganda

\begin{tabular}{lc}
\hline \multicolumn{1}{c}{ Jenis Statistik } & Nilai Statistika \\
\hline Mean & 18,597 \\
Standar Deviasi & 6,441 \\
Koefisien Reabilitas & 0,780 \\
Rata-Rata Tingkat Kesukaran & 0,397 \\
Rata-Rata Daya Pembeda & 0,347 \\
\hline
\end{tabular}

Tabel 11 menunjukkan bahwa koefisien reliabilitas 0,780 sehingga instrumen tes akhir pilihan ganda memiliki reabilitas yang tinggi. Tingkat kesukaran soal masih dalam kategori sedang dengan rata-rata 0,397 . Sedangkan rata-rata daya pembeda yaitu 0,347 berarti instrumen tes pilihan ganda dapat mampu membedakan peserta didik kelompok atas dan kelompok bawah. Analisis selanjutnya adalah analisis instrumen tes HOTS akhir essay, penjelasannya sebagai berikut.

Tabel 12.Tingkat Kesukaran Instrumen Tes HOTS Akhir Essay

\begin{tabular}{lcc}
\hline Butir Soal & Kategori & Persentase $(\%)$ \\
\hline 3 & Sukar & 20 \\
$1,2,4,5$ & Sedang & 80 \\
- & Mudah & - \\
\hline
\end{tabular}

Hasil analisis tingkat kesukaran soal essay produk akhir terdapat 1 soal sukar dan 4 soal berkategori sedang. Berarti sudah tidak ada soal yang termasuk mudah. Selanjutnya, analisis daya pembeda soal essay dijelaskan sebagai berikut.

\begin{tabular}{|c|c|c|}
\hline Butir Soal & Kategori & Persentase (\%) \\
\hline 3,4 & Baik & 40 \\
\hline $1,2,5$ & Diterima tanpa revisi & 60 \\
\hline- & Diterima dengan revisi & - \\
\hline- & Diganti & - \\
\hline
\end{tabular}

Pada Tabel 13 terlihat bahwa 3 soal dapat diterima tanpa revisi dan 2 soal sudah termasuk kategori baik. Setelah semua analisis maka ringkasan statistik instrumen tes HOTS akhir soal essay dijabarkan pada tabel di bawah ini.

Tabel 14. Statistik Hasil Analsis Instrumen Tes HOTS Akhir Essay

\begin{tabular}{lc}
\hline \multicolumn{1}{c}{ Jenis Statistik } & Nilai Statistika \\
\hline Mean & 34,413 \\
Standar Deviasi & 12,142 \\
Koefisien Reabilitas & 0,868 \\
Rata-Rata Tingkat Kesukaran & 0,463 \\
Rata-Rata Daya Pembeda & 0,562 \\
\hline
\end{tabular}


Tabel 14 menjelaskan bahwa koefisien reliabilitas instrumen tes akhir essay adalah 0,868 maka reabilitas soal essay tinggi. Rata-rata tingkat kesukaran adalah 0,463 berarti soal-soal pada tes ini adalah sedang. Sedangkan rata-rata daya pembeda yaitu 0,562 berarti instrumen tes pilihan ganda dapat mampu membedakan peserta didik kelompok atas dan kelompok bawah.

\section{PEMBAHASAN}

Dalam meningkatkan mutu pendidikan khususnya pada pelajaran matematika diperlukan penguasaan materi yang cukup serta pembiasaan dalam menyelesaikan soal atau instrumen yang memacu tingkat berpikir. Susanti dan Nurfitriyanti (2018 : 130) menyatakan bahwa masih banyak siswa yang merasa kesulitan dalam menghadapi soal-soal yang telah dimodifikasi seperti pada pelajaran Matematika. Siswa lebih mudah mengerjakan soal-soal yang bentuknya sama persis dengan soal yang dicontohkan oleh guru. Oleh karena itu siswa perlu dibiasakan mengerjakan soal-soal yang memiliki daya pikir tinggi atau instrumen asesmen HOTS.

Berdasarkan hasil penelitian maka instrumen asesmen HOTS pada materi himpunan direvisi sebanyak tiga kali yaitu pada tahap perancangan, uji coba terbatas dan uji coba lapangan. Revisi tahap perancangan dilakukan berdasarkan masukan dan komentar dari validator. Validator yang digunakan merupakan 3 ahli pendidikan matematika antara lain 1 orang guru SMP dan 2 orang dosen pendidikan matematika. Revisi pertama ini, instrumen asesmen HOTS diperbaiki dari segi rumusan kalimat, kelengkapan informasi data pada soal, dan indikator yang kurang sesuai dengan soal. Perbaikan kalimat disesuaikan dengan konteks kehidupan sehari-hari agar dapa dipahami dengan baik oleh siswa. Ada beberapa siswa yang tidak mengerti maksud pertanyaan pada soal karena bahasa atau kalimat yang digunakan tidak dimenegrti siswa. soal tes yang kurang sesuai dengan indikator maka diperbaiki kembali sehingga soal menjadi sesuai dengan indikator yang telah ditetapkan sebelumnya. Setelah direvisi maka instrumen tes awal siap untuk diuji coba terbatas.

Revisi tahap kedua dilakukan berdasarkan data hasil uji coba terbatas yang dilakukan kepada 35 siswa SMP Negeri Karawang yang telah mendapatkan materi himpunan. Pada tahap ini siswa diminta menyelesaikan instrumen asesmen HOTS awal yang terdiri dari 15 soal pilihan ganda dan 5 soal essay secara individu. Data hasil uji coba kemudian dianalisis karakteristik perbutir soal. Hasil revisi berupa variasi jawaban pilihan ganda sebagai pengecoh, kalimat pada soal essay, dan tingkat kesukaran soal. Hasil revisi tahap dua dinamakan Instrumen tes HOTS Akhir yang selanjutnya digunakan untuk uji coba lapangan.

Pada uji coba lapangan, instrumen asesmen HOTS diujikan kepada 152 siswa yang tersebar pada SMP Negeri 1 Telukjambe Timur, SMP Negeri 2 Telukjambe Timur, SMP Negeri 1 Karawang Barat, SMP Negeri 2 Karawang Barat. Sekolah dipilih secara random, tidak berdasarkan peringkat sekolah. Revisi pada tahap ketiga ini tidak terlalu banyak, hanya menyimpulkan instrumen tes mana yang dapat diterima tanpa revisi dan yang diterima dengan revisi karena semua instrumen diterima tidak ada yang tidak digunakan. akan tetapi tetap dilakukan analisis seperti tahap kedua yaitu menghitung tingkat kesukaran, daya pembeda, reabilitas instrumen.

Instrumen hasil revisi tahap ketiga bisa digunakan secara umum karena berdasarkan hasil validasi ahli, uji coba terbatas, uji coba lapangan, serta revisi-revisi setiap tahapan maka instrumen asesmen HOTS untuk materi himpunan ini telah memenuhi kriteria valid, reliabel dan kualitas soal yang baik. Kevalidan instrumen didasari oleh persetujuan tiga validator ahli yang menyatakan bahwa instrumen tersebut sudah layak digunakan. sedangkan untuk reabilitas dan kualitas instrumen diperoleh berdasarkan hasil analisis yang telah dilakukan pada uji coba terbatas dan lapangan. 


\section{SIMPULAN}

Berdasarkan hasil penelitian, dapat disimpulkan bahwa penelitian ini menghasilkan produk berupa instrumen asesmen HOTS dengan materi himpunan yang dapat mengukur kemampuan berpikir tingkat tinggi siswa SMP kelas VII. Instrumen asesmen berupa dua macam soal yaitu 15 soal pilihan ganda dan 5 soal essay. Kevalidan instrumen asesmen HOTS telah terjamin dengan pernyataan valida dari tiga validator ahli dan analisis perhitungan tingkat kesukaran, daya pembeda, dan reabilitas. Instrumen soal pilihan ganda dan essay terbukti termasuk reliabel tinggi sehingga instrumen sudah memenuhi persyaratan instrumen yang baik. Sedangkan tingkat kesukaran instrumen tergolong sedang dan daya pembeda soal temasuk kriteria baik.

\section{UCAPAN TERIMA KASIH}

Penelitian ini dapat berjalan dengan baik tidak lepas dari dukungan pihak Universitas Buana Perjuangan Karawang, khususnya LPPM yang telah memberikan kesempatan kepada penulis untuk membuat penelitian. Selain itu, penulis juga berterima kasih kepada pihal sekolah SMP Negeri 1 Karawang Barat, SMP Negeri 2 Karawang Barat, SMP Negeri 5 Karawang Barat, SMP Negeri 1 Telukjambe Timur, SMP Negeri 2 Telukjambe Timur yang telah mengizinkan penulis melakukan penelitian di sekolah yang bersangkautan. Dan tak lupa kepada validator ahli untuk masukan saran dan komentarnya yang membantu perancangan instrumen asesmen HOTS ini.

\section{DAFTAR PUSTAKA}

Airasian, P. (2005). Assessment in The Classroom: A Concise Approach (2nd Ed). Boston: McGraw-Hill Company.

Anderson, L.W., \& Krathwohl, D.R. (2001).A Taxonomy for Learning, Teaching, and Assesing: A Revision of Bloom's Taxonomy of Educational Objective. New York: Addison Wesley Longman In.

Arikunto, S. (2009).Dasar-Dasar Evaluasi Pendidikan. Edisi Revisi Cet. IX . Jakarta: Bumi Aksara

Borg, W.R., \& Gall, M.D. (1983).Educational Researcher: An Introduction, 4th Editon. New York: Longman.

Budiman, A., dan Jailani. (2014). Pengembangan Instrumen Asesmen Higher Order Thinking (HOTS) pada Mata Pelajaran Matematika SMP Kelas VIII Semester 1.Jurnal Riset Pendidikan Matematika. Vol. 1, No. 2, hal.139-151.

Kadir, A. (2015). Menyusun dan Menganalisis Tes Hasil Belajar.Jurnal Al-ta'dib. Vol. 8, No. 2.

NCTM.(1989). Curriculum and Evaluatio Standards for School Mathematics. Reston, VA: The National Council of Teahers of Matematics, Inc.

Poerwanti, E. (2008). Asesmen Pembelajaran SD. Jakarta: Dirjen Pendidikan Tinggi Departemen Pendidikan Nasional.

Resnick, L.B. (1987). Education and Learning to Think. Washington D.C : National Academy Press.

Stein, M.K. and Lane, S. (1996). Instructional Task and The Development of Student Capacity to Think and Reason: An Analysis of The Relationship Between Teaching and Learning in a Reform Mathematics Project. Educational Research and Evaluation, 2 (1), 50-80. 
120Lestari.

Susanti, Sri \& Maya Nurfitriyanti. (2018). Pengaruh Model Realistic Mathematic Education $(R M E)$ terhadap Kemampuan Pemecahan Masalah Matematika. Jurnal Kajian Pendidikan Matematika. Vol. 3, No.2, hal.129-136.

Van de Walle, J. A. (2008). Matematika sekolah dasar dan menengah (6th ed.). (Terjemahan Suyono). Jakarta: Penerbit Erlangga.

Widana, I.W., (2017). Modul Penyusunan Soal Higher Order Thinking Skill (HOTS). Jakarta: Direktorat Pembinaan SMA, Dirjen Pendidikan Dasar dan Menengah, Depdikbud. 